\title{
Tissue sensitive imaging and tomography without contrast agents for small animals with Timepix based detectors
}

Citation for published version (APA):

Trojanova, E., Schyns, L. E. J. R., Dubois, L., Jakubek, J., Le Pape, A., Sefc, L., Sykora, V., Turecek, D., Uher, J., \& Verhaegen, F. (2017). Tissue sensitive imaging and tomography without contrast agents for small animals with Timepix based detectors. Journal of Instrumentation, 12, [01056]. https://doi.org/10.1088/1748-0221/12/01/C01056

Document status and date:

Published: 01/01/2017

DOI:

10.1088/1748-0221/12/01/C01056

Document Version:

Publisher's PDF, also known as Version of record

Document license:

Taverne

Please check the document version of this publication:

- A submitted manuscript is the version of the article upon submission and before peer-review. There can be important differences between the submitted version and the official published version of record.

People interested in the research are advised to contact the author for the final version of the publication, or visit the DOI to the publisher's website.

- The final author version and the galley proof are versions of the publication after peer review.

- The final published version features the final layout of the paper including the volume, issue and page numbers.

Link to publication

\footnotetext{
General rights rights.

- You may freely distribute the URL identifying the publication in the public portal. please follow below link for the End User Agreement:

www.umlib.nl/taverne-license

Take down policy

If you believe that this document breaches copyright please contact us at:

repository@maastrichtuniversity.nl

providing details and we will investigate your claim.
}

Copyright and moral rights for the publications made accessible in the public portal are retained by the authors and/or other copyright owners and it is a condition of accessing publications that users recognise and abide by the legal requirements associated with these

- Users may download and print one copy of any publication from the public portal for the purpose of private study or research.

- You may not further distribute the material or use it for any profit-making activity or commercial gain

If the publication is distributed under the terms of Article $25 \mathrm{fa}$ of the Dutch Copyright Act, indicated by the "Taverne" license above, 
$18^{\text {TH }}$ International Workshop on Radiation Imaging Detectors

3-7 JULY 2016,

Barcelona, Spain

\title{
Tissue sensitive imaging and tomography without contrast agents for small animals with Timepix based detectors
}

\author{
E. Trojanova, ${ }^{a, d, 1}$ L.E.J.R. Schyns, ${ }^{b}$ L. Dubois, ${ }^{b}$ J. Jakubek, ${ }^{a}$ A. Le Pape, ${ }^{c}$ L. Sefc, ${ }^{d}$
} V. Sykora, ${ }^{d}$ D. Turecek, ${ }^{a}$ J. Uher ${ }^{a}$ and F. Verhaegen ${ }^{b}$

\author{
${ }^{a}$ ADVACAM s.r.o., \\ Na Balkańě 2075/70, Prague, Czech Republic \\ ${ }^{b}$ Department of Radiation Oncology (MAASTRO), \\ GROW - School for Oncology and Developmental Biology, Maastricht University Medical Centre, \\ Maastricht, the Netherlands \\ ${ }^{c}$ Centre for Small Animal Imaging (CIPA), TAAM - Transgénèse et Archivage d'Animaux Modèles, \\ 3 B, Rue de la Férolerie, Orleans, France \\ ${ }^{d}$ Center for Advanced Preclinical Imaging (CAPI), First Faculty of Medicine, Charles University, \\ Salmovska 3, Prague, Czech Republic
}

E-mail: eliska.trojanova@advacam.com

AвSTRACT: The tissue type resolving X-ray radiography and tomography can be performed even without contrast agents. The differences between soft tissue types such as kidney, muscles, fat, liver, brain and spleen were measured based on their spectral response. The Timepix based X-ray imaging detector WidePIX ${ }_{2 \times 5}$ with $300 \mu \mathrm{m}$ thick silicon sensors was used for most of the measurements presented in this work. These promising results are used for further optimizations of the detector technology and radiographic methods.

KeYwords: Pixelated detectors and associated VLSI electronics; Spectral responses; X-ray detectors; X-ray radiography and digital radiography (DR)

\footnotetext{
${ }^{1}$ Corresponding author.
} 


\section{Contents}

1 Introduction 1

2 Principle and methods 2

2.1 Hybrid photon counting detector Timepix 2

2.2 Energy discrimination: thresholding 2

2.3 Energy sensitive transmission radiography or "Colour imaging" 3

2.4 Transfer the grayscale image to the colour image 3

2.5 Energy sensitive transmission radiography 4

3 3D imaging method: computed tomography 4

3.1 Tissue sensitive computed tomography 5

3.2 Spectral responses of different tissue types 5

4 Summary and conclusions $\quad 7$

\section{Introduction}

The soft tissue X-ray imaging methods gain greater and greater importance in determining anatomical and physiological changes and processes, particularly those specific to various diseases. The methods allow acquiring information about the extent, morphological and structural changes of individual organs or tissue structures influenced by disease or therapeutic procedures. Such information helps to indicate the presence of disease, monitor its evolution, help to determine the most optimal therapy and to improve the visibility of the tumor and to improve the accuracy of Monte Carlo dose calculations (for which different materials/tissues need to be assigned correctly).Animal models are often used for pre-clinical studies. The goal of our work is to find the new approach to conduct experiments with animals more accurately and efficiently.

The advantages of energy sensitive X-ray radiography with photon counting pixel detectors in the field of small animal imaging were already demonstrated [1]. Those are namely: high spatial resolution, good imaging contrast and energy sensitivity. It is known that different soft tissue types have a very similar elemental composition. Therefore, it is difficult to identify them in regular radiographic images. Contrast agents are commonly used for this reason. They allow highlighting certain tissue types based on uptake of the selected contrast agent in a target tissue or organ. It was shown that the energy sensitive tomography of a mouse performed with Medipix3 imaging detector can distinguish even several contrast agents simultaneously [2]. In this work, we show that a proper measurement of an X-ray spectrum transmitted through the biological sample allows even for direct tissue type identification without any contrast agent.

The spectral measurements presented in this work were performed with a photon counting imaging detector based on the Timepix technology [3] within a standard tomographic setup with 
a mini-focus X-ray tube. Each tomographic projection was measured at multiple energy discrimination thresholds. The evaluation method presented here was comparative. I.e. it compares a spectral response of a particular sample location with known tissue types. We show that this X-ray imaging method allows identification of tissue types with similar overall X-ray attenuation levels even without contrast agent.

\section{Principle and methods}

\subsection{Hybrid photon counting detector Timepix}

The hybrid semiconductor pixel detector Timepix registers individual ionizing particles such as X-ray photons digitally. The detector consists of readout and sensor chips ( $\mathrm{Si}, \mathrm{CZT}, \mathrm{CdTe}, \ldots$ ), which are connected using the bump-bonding technology. The sensor chip is equipped with one common electrode on the back side and an array of pixel electrodes on the other side. The pixel array consists of $256 \times 256$ square pixels with $55 \mu \mathrm{m}$ pitch. Each element of matrix (pixel) is connected to an appropriate preamplifier, energy discriminator and digital counter integrated on the readout chip. The sensitive area of a single Timepix detector is $1.4 \times 1.4 \mathrm{~cm}^{2}$. Larger sensitive surfaces are created by placing many Timepix detector tiles next to each other [4] (see figure 1).
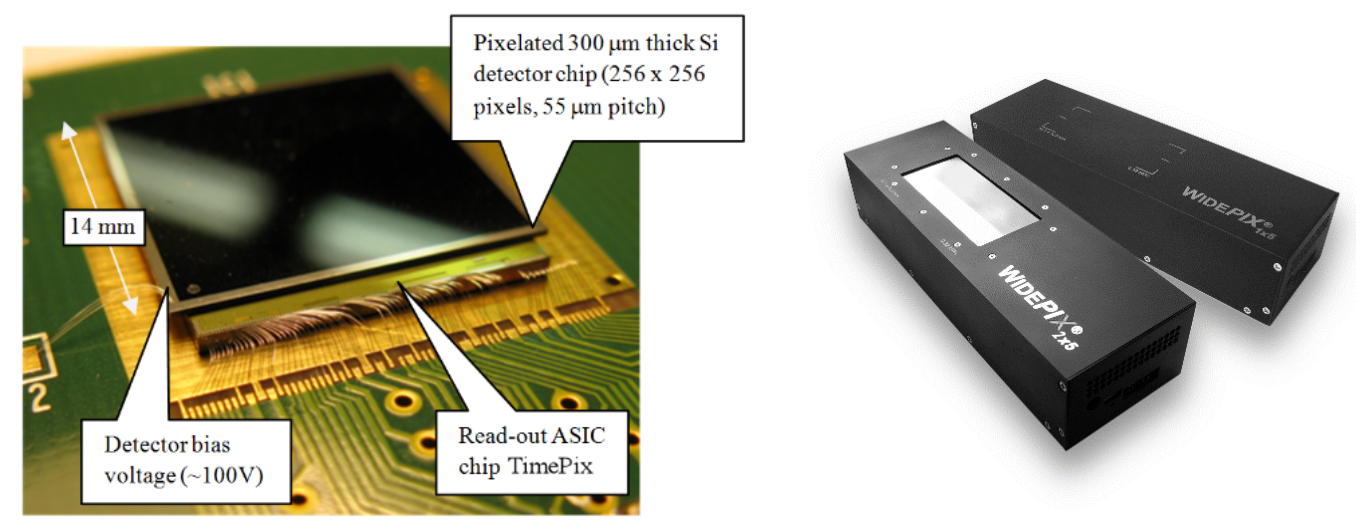

Figure 1. Left — Single Timepix device with planar silicon sensor. Right - The WidePIX $2 \times 5$ or WidePIX $1 \times 5$ detectors consisting of ten or five Timepix devices arranged in matrix of $2 \times 5$ or $1 \times 5$ tiles. The sensor material of these detectors is either Silicon or CdTe. The silicon detector version is used for radiography of light or thin objects e.g. soft tissue structures.

The major benefits of these detectors are: the theoretically unlimited dynamic range (the signal to noise ratio (SNR) increases with longer exposure time), the high read-out speed, no dark current and the energy sensitivity.

\subsection{Energy discrimination: thresholding}

The energy discrimination threshold function allows to limit the detector sensitivity only to Xray photons of energy above a certain preselected energy. The Timepix detector can work in three principal modes of operation as depicted in figure 2. The basic mode is so called Medipix mode where each pixel counts particles (photons) with energy over the threshold. The Time-overThreshold (ToT) mode allows for the direct energy measurement of every detected particle in each 


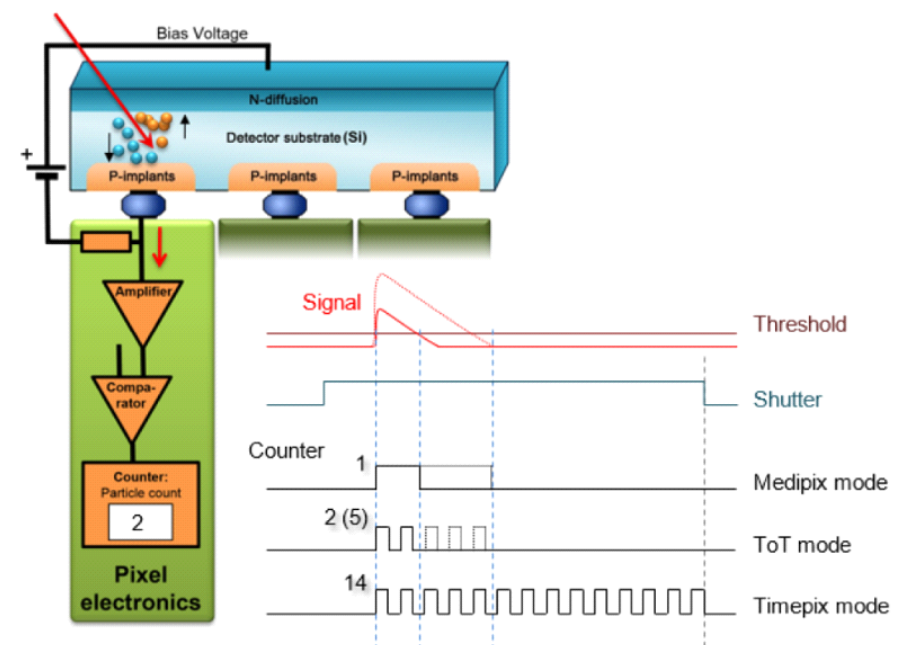

Figure 2. Simplified diagram of Timepix function in different modes of operation. The Medipix mode is used for counting of ionizing particles (e.g. X-ray photons) delivering energy above preselected threshold.

pixel. The third mode (Timepix mode) measures the time of arrival of the first particle interacting within a pixel. This mode is usually not used for radiography, though.

We used Medipix mode (counting) for radiographic measurements presented in this work since the ToT mode requires very low radiation intensity and long measurement times that are impractical in radiographic and tomographic measurements.

The counting mode with the energy thresholding feature is sufficient for measurement and separation of different energy bands of the spectrum. The threshold value is set in kiloelectrovolts $(\mathrm{keV})$. Since there is just a single threshold level available in the Timepix device, integral X-ray spectra are measured by performing a threshold scan. Typically, only a few energy windows are used for radiography.

\subsection{Energy sensitive transmission radiography or "Colour imaging"}

The attenuation of X-ray radiation by a specific material depends on its energy. The shape of such dependence (the X-ray transmission curve) is specific for each material with certain elemental composition [5]. The material information can be obtained even if the transmitted spectra are measured in a crude fashion by binning the entire energy range into a few energy bins. This basic technique is similar to colour photography and it is often called "Colour" X-ray transmission imaging.

Energy sensitive radiography with a Timepix detector makes use of the threshold function to resolve and emphasize differences in the transmitted spectra. A sequence of X-ray images is taken at different energy thresholds. The energy sensitive X-ray transmission radiography allows to resolve materials differing in elemental composition.

\subsection{Transfer the grayscale image to the colour image}

Each pixel is capable of discriminating X-ray photons based on their energy as shown in the following figure 3 . Several energy channels are measured by setting the threshold to different levels. 
Colour X-ray images are created by associating the red, green and blue channels of the final image with the measured intensities of X-rays at different energies. The blue channel counts for high energy photons. The green band represent photons with middle energy values and the red band shows the lowest energies (see figure 3).
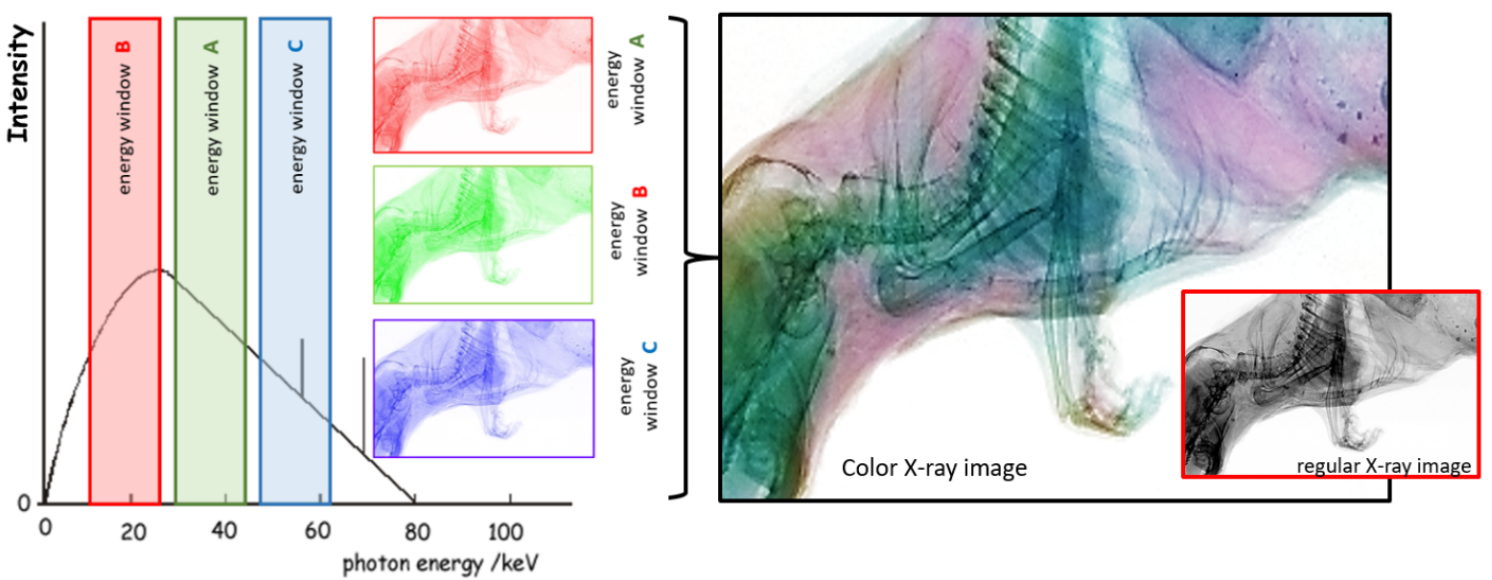

Figure 3. The principle and example of colour X-ray imaging are shown. The preselected energy bands of the transmitted X-ray beam are directly mapped to colours (RGB colours in this case).

Individual channels represent the visibility of different materials based on their spectral response (absorption curve). The resulting images are obtained by combining these energy bands and mapping them to the basic RGB colours (red, green and blue). The method of energy weighting is often used for material decomposition or separation (e.g. selective image of contrast agent distribution only). There are many other methods of "mixing" the measured signals in energy bands to enhance contrast of specific materials or structures.

\subsection{Energy sensitive transmission radiography}

The ability to discriminate tissue type using energy sensitive X-ray radiography [6] was tested with several simple samples: muscle tissue with fat or chicken wing. The weight of the colour was assigned to every pixel according to the distance of the measured attenuation curve in this pixel from each reference curve (see figure 4). It is shown that materials like a fat, a muscle, a liver and bones (indeed) can be clearly resolved. The example image of bacon is shown in figure 4 .

\section{3D imaging method: computed tomography}

A tomographic measurement (scan) is performed by taking transmission X-ray radiographic images of the object at different observation angles (projections). Typically, hundreds or even thousands of such projections are recorded. These projections are subsequently used as input for a tomographic reconstruction algorithm which computes the $3 \mathrm{D}$ volumetric model of the inspected object. The 3D model is usually stored as a 3D matrix where each cell (called voxel) contains information proportional to the X-ray attenuation coefficient and density of the sample at that point.

The method of material (or tissue) sensitive radiography can be combined with a tomographic scan simply by measuring projections at multiple energy levels using the energy discrimination 


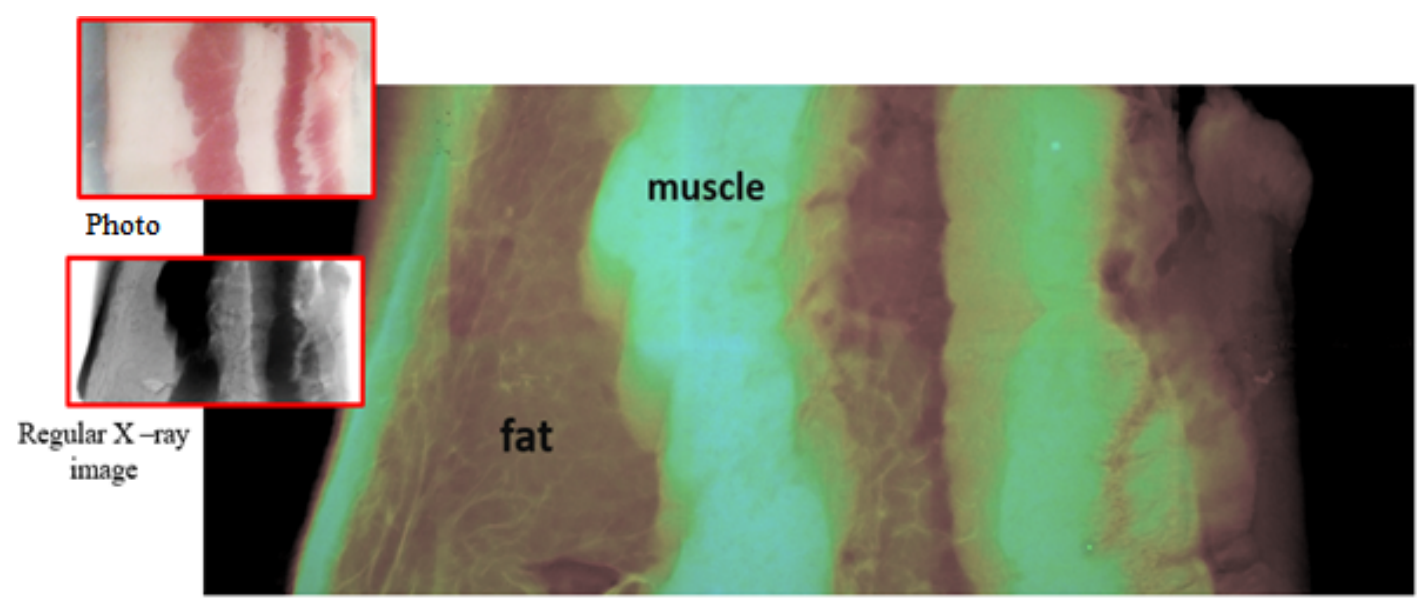

Figure 4. X-ray color image of muscle tissue and fat. The X-ray tube was operated at $60 \mathrm{kVp}$ and $120 \mu \mathrm{A}$. The threshold scan was performed under thresholds from 5 to $30 \mathrm{keV}$ with step $2.5 \mathrm{keV}$.

threshold. The tomographic reconstruction can be then applied for each of energy level independently resulting in multiple 3D models. Each model is thus calculated for a different energy level. The final colour visualisation is achieved in the same way to described in the section 2.4

For purposes of this work the stationary tomographic setup with a rotating sample stage was used. The algorithms of cone beam filtered back projection (FBP) were used for $3 \mathrm{D}$ reconstructions of the measured data.

\subsection{Tissue sensitive computed tomography}

A plastinated mouse $[7,8]$ produced by the Smart Scientific Solutions company was used as the first sample for preliminary measurements using spectral Computed Tomography (CT). Detector WidePIX $_{2 \times 5}$ with silicon sensors was used for all measurements. The X-ray tube was operated at $60 \mathrm{kVp}$ and $120 \mu \mathrm{A}$ and threshold levels of $10,15,25$ and $30 \mathrm{keV}$ were used. The threshold values were always selected based on experience and applied voltage. 200 projections were measured in total. The filtered back projection algorithm was used for reconstructions. Resulting colour X-ray images based on spectral response are shown in figure 5. The process of plastination replaces water and fat in the sample with a plastic. This makes the differences between different types of tissue smaller than in unplastinated organs. However, even in spite of that, volumes of different tissue types were identified.

The subsequent experiment was performed with a real in vivo mouse body, when the X-ray tube was operated at $60 \mathrm{kVp}, 70 \mathrm{kVp}$ and $80 \mathrm{kVp}$. The current $80 \mu \mathrm{A}$ was selected for all of these measurements (figure 6). The best results were obtained when have been set the following parameters of the X-ray tube: voltage at $60 \mathrm{kVp}$ and current at $80 \mu \mathrm{A}$.

\subsection{Spectral responses of different tissue types}

The next topic of this work was an evaluation of the magnitude of the differences in spectral responses measured by the Timepix detector for different soft tissue types as well as an initial test of repeatability of the spectral responses for imaging of different animal specimens. 

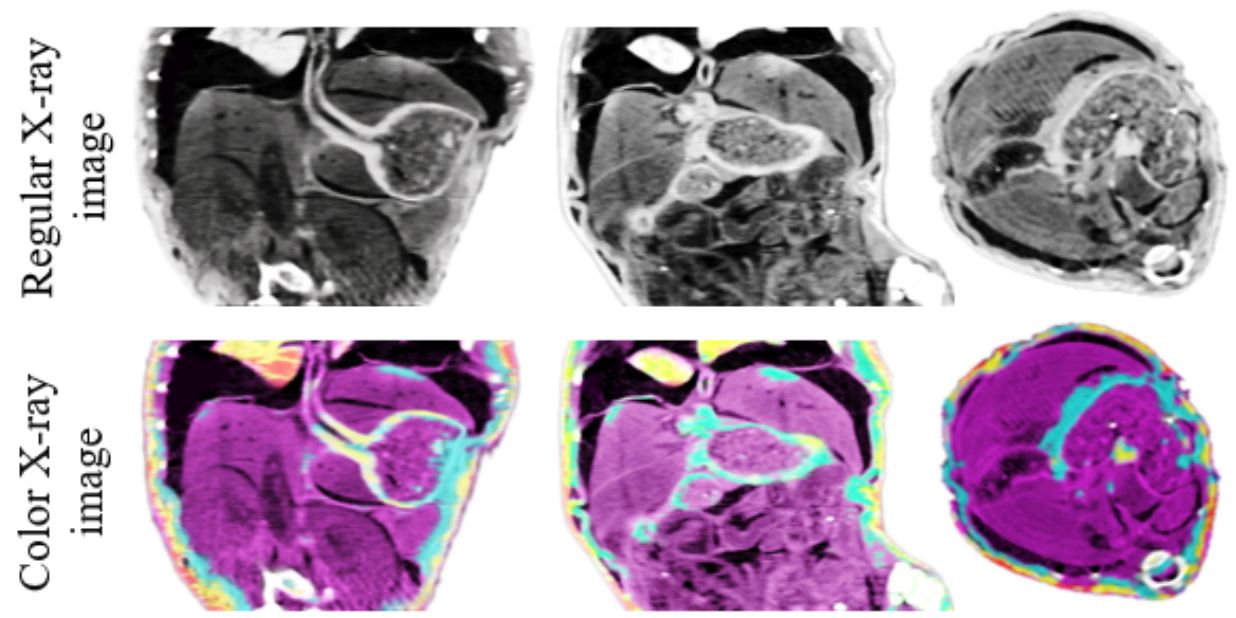

Figure 5. Upper set of images shows regular CT slices (abdominal part). Bottom set of images represents tissue identified slices where colour correspond to different tissue types. The brightness corresponds to the scaling factor (density).

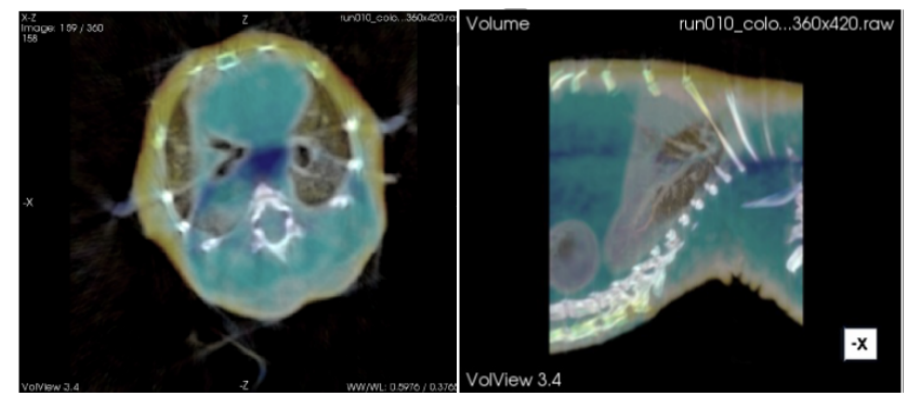

Figure 6. CT slices through the mouse lung. Colours represent differences in tissue type spectral response differences brightness corresponds to the density.

The energy sensitive X-ray measurements were performed using frozen samples of mice tissues. Samples were taken from two mice for comparison. The following soft tissue samples were studied: liver, brain, lung, muscle, fat, unspecified tumour (H460 NSCLC xenograft ), kidney, heart and spleen.

The threshold scan was conducted for each sample for thresholds in ranging from 5 to $35 \mathrm{keV}$ with step of $2.5 \mathrm{keV}$ and the resulting integral spectra were differentiated. Spectral response was calculated for each tissue sample according to the following general formula describing the X-ray absorption in every energy channel:

$$
\mu\left(E_{i}\right)=-\frac{1}{t_{\mathrm{eff}}} \ln \frac{I\left(E_{i}\right)}{I_{0}\left(E_{i}\right)}, \quad \hat{\mu}\left(E_{i}\right)=\frac{\mu\left(E_{i}\right)}{\mu_{\mathrm{ref}}\left(E_{i}\right)} .
$$

Where $E_{i}$ is energy of $i$-th energy channel, $I_{0}\left(E_{i}\right)$ is the input radiation intensity for energy channel $E_{i}, I\left(E_{i}\right)$ is the measured radiation intensity transmitted through the sample at the energy channel $E_{i}, \mu$ is the linear attenuation coefficient for energy channel $E_{i}$ and $t_{\mathrm{eff}}$ is the effective thickness (i.e. the thickness divided by density). 
The calculated values of $\mu\left(E_{i}\right)$ are further normalized by reference the attenuation curve $\mu_{\text {ref }}\left(E_{i}\right)$ measured with a muscle sample resulting in a relative attenuation curve $\hat{\mu}$. Several curves $\hat{\mu}$ measured for three different tissue types are plotted in figure 7 . There is clear difference in shapes of these curves for different tissue types. A very good agreement was found for same tissue types of both mice.
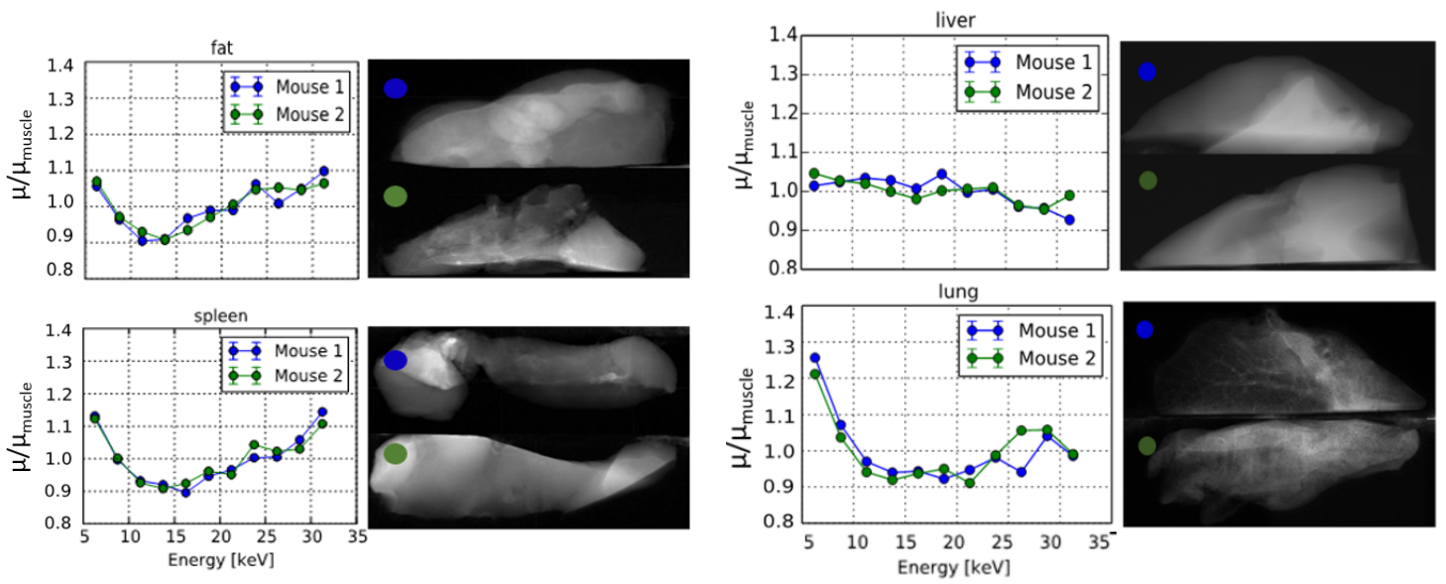

Figure 7. Attenuation curves for different tissues types relative to curve of muscles in mouse 1. The X-ray tube was operated at $60 \mathrm{kVp}$ and $120 \mu \mathrm{A}$. A threshold scan from 5 to $30 \mathrm{keV}$ with a step of $2.5 \mathrm{keV}$ was performed for each sample.

\section{Summary and conclusions}

It was shown that the energy sensitive $\mathrm{X}$-ray transmission radiography and tomography with photon counting imaging detectors can distinguish and visualize basic soft tissue types in small animal samples even without contrast agents. Our work suggests that multiple tissue types such as lungs, spleen, brain, fat or muscle can be distinguished and mapped during single CT scan. Achieving "colour X-ray" imaging presents real added value for the biological research and medical diagnostics. This technology is also applicable in other X-ray applications such as non-destructive testing, material studies, luggage inspection, etc.

\section{Acknowledgments}

The work was supported by project TA04011329 granted by Technology Agency of the Czech Republic, by Project the MEYS CR (LM2015062 Czech-BioImaging, by PRVOUK-P24/LF1/3 of the Charles University - First Faculty of Medicine and partially also supported by Project No. LO1219 of the Ministry of Education, Youth and Sports. The work was carried out in frame of the Medipix Collaboration based at CERN.

\section{References}

[1] P. Delpierre et al., XPAD: A photons counting pixel detector for material sciences and small-animal imaging, Nucl. Instrum. Meth. A 572 (2007) 250. 
[2] M. Firsching et al., Contrast agent recognition in small animal CT using the Medipix2 detector, Nucl. Instrum. Meth. A 607 (2009) 179.

[3] M. Jakubek et al., Large area pixel detector WIDEPIX with full area sensitivity composed of 100 Timepix assemblies with edgeless sensors, 2014 JINST 9 C04018.

[4] X. Llopart, R. Ballabriga, M. Campbell, L. Tlustos and W. Wong, Timepix, a 65k programmable pixel readout chip for arrival time, energy and/or photon counting measurements, Nucl. Instrum. Meth. A 581 (2007) 485 [Erratum ibid. A 585 (2008) 106-108].

[5] J. Jakubek, Energy-sensitive X-ray radiography and charge sharing effect in pixelated detector, Nucl. Instrum. Meth. A 607 (2009) 192.

[6] E. Schioppa, The color X-Ray: Spectral X-ray computed tomography using energy sensitive pixel detectors, Uitgeverij BOXPress, 's-Hertogenbosch (2014).

[7] The plastinated mouse, http://www.smartscientificsolutions.com.

[8] G. von Hagens, K. Tiedemann and W. Kriz, The current potential of plastination, Anat. Embryol. 175 (1987) 411. 